\title{
Educational Impact of Mini-CEX Using Clinical Encounter Card System among Obstetrics and Gynecology Residents in a Tertiary Care Hospital
}

\author{
Amtullah Zarreen
}

\begin{abstract}
Objective: To assess the educational impact of implementing mini-CEX clinical encounter card system to the residents in obstetrics and gynecology.

Study Design: Quasi-experimental study.

Place and Duration of Study: Gynecology Unit 1, Jinnah Hospital, Allama Iqbal Medical College, Lahore, from April 2016 to March 2017.

Methodology: In this prospective study, a total of 64 encounters were assessed in eight residents by three assessors using mini-CEX Clinical Encounter Card System (CEC). Scores were awarded and entered on the card. Cronbach's alpha was calculated to check reliability of the mini-CEX items.

Results: In the first encounter, three (37.5\%) residents had unsatisfactory overall skills, while five $(62.5 \%)$ had satisfactory and none had superior skills. However, at the eighth assessment, none of the resident had unsatisfactory skills, six (75\%) had satisfactory skills, while two (25\%) had superior skills. Cronbach's alpha was calculated as 0.894 , which shows high reliability. Statistically significant differences $(p<0.05)$ were observed in medical interviewing skills (MIS), physical examination skills (PES) and organizational efficiency (OE).

Conclusion: Mini-CEX is an acceptable and practical tool for assessment of residents during training. The study showed marked improvement in the overall skills of the residents. It was found to be feasible within the daily working in OPD and Indoor wards. Both faculty and residents have accepted it very well.
\end{abstract}

Key Words: Medical education, Mini-CEX, Postgraduate training.

\section{INTRODUCTION}

Currently there is increasing emphasis on defining outcomes in medical education, or in other words on "performance" rather than "competence". The principles of competency-based medical education (CBME) stress on the effective evaluation of these outcomes and on the feedback by faculty. 1

In countries like Pakistan, workload on residents is quite high in public sector hospitals, especially in the discipline of obstetrics and gynecology. Usually, there is no time for structured formative assessment of their basic clinical skills and more importantly for giving them feedback. Due to lack of appropriate feedback, some deficiencies may remain unidentified and thus uncorrected. ${ }^{2}$

OSCE and TOACS have been used for many years to assess residents' competence in a simulated environment. These assessment tools only assess competence (what

Department of Obstetrics and Gynecology, Allama Iqbal Medical College and Jinnah Hospital, Lahore, Pakistan

Correspondence: Prof. Amtullah Zarreen, Head, Department of Obstetrics and Gynecology, Allama Iqbal Medical College and Jinnah Hospital, Lahore, Pakistan

E-mail:az30b@yahoo.com

Received: April 03, 2018; Accepted: August 09, 2018 a trainee can do) and not the actual performance. It is quite difficult to assess residents' overall clinical competence and how he/she would perform in practice, without being in a real life situation, i.e. without an actual patient encounter.

Mini-CEX is a novel assessment tool which involves direct observation of residents' clinical skills in an encounter with the real patient at workplace. The clinical faculty acts as observers/assessors. ${ }^{3}$ Thus, it is more of an assessment of performance (what a trainee actually does) than competence (trainee's capability of doing).

Mini clinical examination (Mini-CEX) is a structured and validated tool which has been in use in the past to assess overall clinical skills of the residents through clinical encounter cards. ${ }^{4}$ It uses a 9-point Likert scale categorising the scores on eight different domains as 1 to 3 as unsatisfactory, 4 to 5 as satisfactory and 7 to 9 as superior. Starting with the assessment of basic history taking and examination skills, followed by application of knowledge, problem formulation and diagnosis, and professionalism are assessed in real clinical encounter with patient.5,6 The assessor rates the resident on various parameters and documents the scores.

The objective of this study was to assess the educational impact of mini-CEX on the residents of obstetrics and gynecology. 


\section{METHODOLOGY}

This prospective study was conducted in the Obstetrics and Gynecology Unit I, Allama lqbal Medical College Jinnah Hospital, Lahore, from April 2016 to March 2017. Residents with more than one year training after FCPS part 1 and willing to participate were included in the study and their consent was taken. All the participating residents completed eight encounters each with no drop out. A total of eight residents of obstetrics and gynecology were subjected to mini-CEX using clinical encounter card (CEC) system by three assessors and each resident was assessed eight times. Each encounter spanned with the duration of approximately 20-25 minutes, while 05-10 minutes were allocated for feedback from the assessor to the resident.

Sample size was calculated using sample size calculator World Health Organization version 2.0.21 employing the impact of mini-CEX, 7 on improvement in clinical performance as $6.53 \pm 1.60$. The sample size was calculated to be 62 observations; however, this study reports 64 observations.

A total of 64 observations were made in OPD and ward on real patients after obtaining their consent. The main exposure variable was the introduction of mini-CEX clinical encounter card and its impact was assessed on different domains of clinical skills using 9-point Likert scale. The assessments were labelled as unsatisfactory if the scores were between 1-3, satisfactory if the scores were between 4-6 and, superior if the scores were between 7-9. Cronbach's alpha was calculated to measure the reliability of items included in the questionnaire.

Data from clinical encounter cards (CEC) were entered and analysed using SPSS version 17 . Mean and SD were calculated for quantitative variables like MIS, PES, Problem Formulation and Diagnosis, Problem Solving and Management, Professionalism, Counselling Skills, $\mathrm{OE}$ and Overall Clinical Competence (OCC) scores. Frequencies and percentages were calculated to present level of performance of residents. Cronbach's alpha was calculated to check the reliability of mini-CEX. Repeated measures ANOVA was applied to find out the improvement in mean score from first to eighth encounter. $P$-value of $<0.05$ was considered as significant.
After completion of eight encounters, participants' perception about the implementation of mini-CEX was sought through a pre-designed structured questionnaire. Content analysis was done for open-ended questions in the questionnaire.

\section{RESULTS}

The entire exercise was participated by three assessors and eight residents. All residents and assessors were female. The complexity level of the cases was low, moderate and high. Out of 64 encounters, $45(70.31 \%)$ patients were of moderate complexity, 15 (23.44\%) were of low complexity and only 4 (6.25\%) were highly complex cases.

Overall Cronbach's alpha was calculated as 0.894 , which shows high reliability of mini-CEX items. Mean scores and SD on all the eight competencies observed during eight clinical encounters were calculated. (Table I). There was significant improvement in the mean scores, i.e. $p$-value $<0.05$ from encounter 1 to encounter 8 in all domains of clinical competence assessed by mini-CEX.

Medical interviewing (MI), physical examination skills (PES), organisational efficiency (OE), and overall clinical competency (OCC) showed marked improvement.

In first encounter, three (37.5\%) residents had unsatisfactory skills, while five (62.5\%) had satisfactory skills, and none was found superior (Figure 1). However, at the eighth encounter, none of the residents had unsatisfactory skill, six (75\%) residents had satisfactory, and 2 residents $(25 \%)$ had superior skills. The impact of miniCEX on overall clinical competency is shown in Figure 2.

All assessors and residents were satisfied with the conduct of each clinical encounter. The mean scores for residents' overall satisfaction with the mini-CEX, increased from 4.13 in the first to 5.50 in the eighth encounter and SD decreased from 1.55 to 1.07 .

\section{DISCUSSION}

Mini-CEX is one of the most widely used tools for assessment of trainees' performance at workplace. Out of the five components of utility of mini CEX, i.e. educational impact, validity, reliability, acceptability and

Table I: Mean scores and SD on competencies observed during eight clinical encounters.

\begin{tabular}{|c|c|c|c|c|c|c|c|c|c|c|c|c|c|c|c|c|}
\hline \multirow[t]{2}{*}{$\begin{array}{l}\text { Encounter } \\
\text { number }\end{array}$} & \multicolumn{2}{|c|}{$\begin{array}{c}\text { Medical } \\
\text { interviewing } \\
\text { skills }\end{array}$} & \multicolumn{2}{|c|}{$\begin{array}{c}\text { Physical } \\
\text { examination } \\
\text { skills }\end{array}$} & \multicolumn{2}{|c|}{$\begin{array}{l}\text { Problem } \\
\text { formulation/ } \\
\text { diagnosis }\end{array}$} & \multicolumn{2}{|c|}{$\begin{array}{c}\text { Problem } \\
\text { solving/ } \\
\text { management }\end{array}$} & \multicolumn{2}{|c|}{ Professionalism } & \multicolumn{2}{|c|}{$\begin{array}{l}\text { Counseling } \\
\text { skills }\end{array}$} & \multicolumn{2}{|c|}{$\begin{array}{l}\text { Organizational } \\
\text { efficiency }\end{array}$} & \multicolumn{2}{|c|}{$\begin{array}{c}\text { Overall } \\
\text { clinical } \\
\text { competency }\end{array}$} \\
\hline & Mean & SD & Mean & SD & Mean & SD & Mean & SD & Mean & SD & Mean & SD & Mean & SD & Mean & SD \\
\hline 1 & 4.25 & 1.49 & 3.88 & 1.36 & 4.13 & 1.13 & 4.25 & 0.71 & 3.75 & 0.89 & 3.63 & 0.74 & 3.38 & 1.19 & 3.88 & 0.83 \\
\hline 2 & 3.88 & 0.99 & 3.50 & 0.53 & 3.88 & 0.99 & 4.38 & 0.74 & 3.63 & 0.92 & 4.25 & 0.71 & 3.88 & 0.83 & 3.88 & 0.83 \\
\hline 3 & 4.50 & 1.41 & 3.75 & 1.16 & 4.25 & 1.04 & 4.38 & 0.92 & 4.50 & 1.07 & 4.13 & 0.83 & 4.13 & 0.83 & 4.13 & 0.83 \\
\hline 4 & 4.50 & 1.41 & 4.38 & 1.30 & 5.00 & 0.93 & 4.63 & 0.92 & 4.75 & 0.89 & 4.75 & 0.89 & 4.75 & 0.89 & 4.88 & 0.83 \\
\hline 5 & 5.00 & 1.20 & 4.38 & 1.51 & 5.25 & 1.04 & 5.25 & 1.28 & 4.50 & 1.20 & 4.75 & 1.04 & 5.00 & 1.07 & 4.88 & 0.83 \\
\hline 6 & 4.38 & 0.52 & 4.25 & 0.71 & 5.00 & 0.76 & 4.88 & 0.83 & 4.63 & 0.74 & 4.63 & 1.19 & 3.88 & 0.83 & 4.63 & 0.92 \\
\hline 7 & 5.25 & 0.71 & 5.25 & 0.46 & 4.75 & 0.71 & 5.13 & 0.64 & 4.75 & 0.71 & 4.75 & 0.71 & 4.88 & 0.35 & 4.88 & 0.64 \\
\hline 8 & 5.88 & 0.99 & 5.75 & 0.71 & 5.38 & 0.52 & 5.50 & 0.76 & 5.50 & 0.93 & 5.38 & 0.92 & 5.75 & 0.71 & 5.38 & 0.74 \\
\hline$p$-value & \multicolumn{2}{|c|}{0.000} & \multicolumn{2}{|c|}{0.000} & \multicolumn{2}{|c|}{0.000} & \multicolumn{2}{|c|}{0.000} & \multicolumn{2}{|c|}{0.000} & \multicolumn{2}{|c|}{0.000} & \multicolumn{2}{|c|}{0.000} & \multicolumn{2}{|c|}{0.000} \\
\hline
\end{tabular}



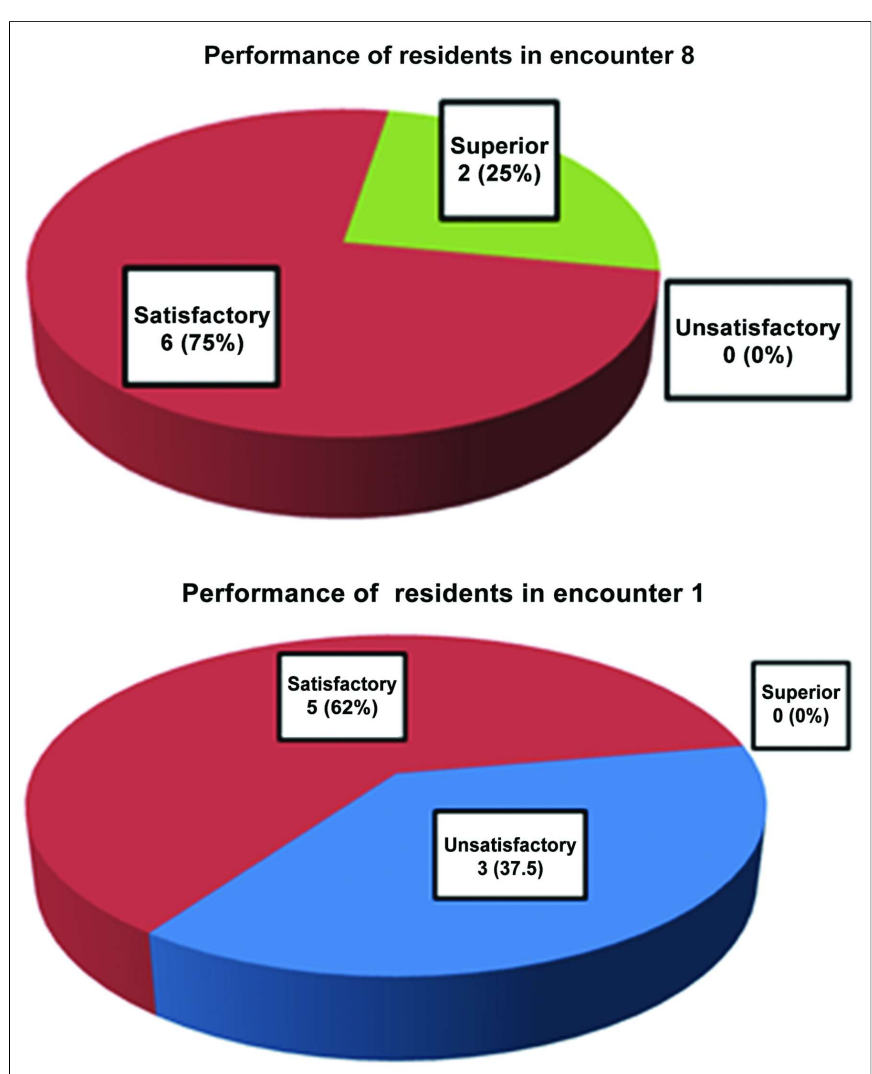

Figure 1: Above diagrams show the proportion of residents' performance at first (a) and last (b) encounters.

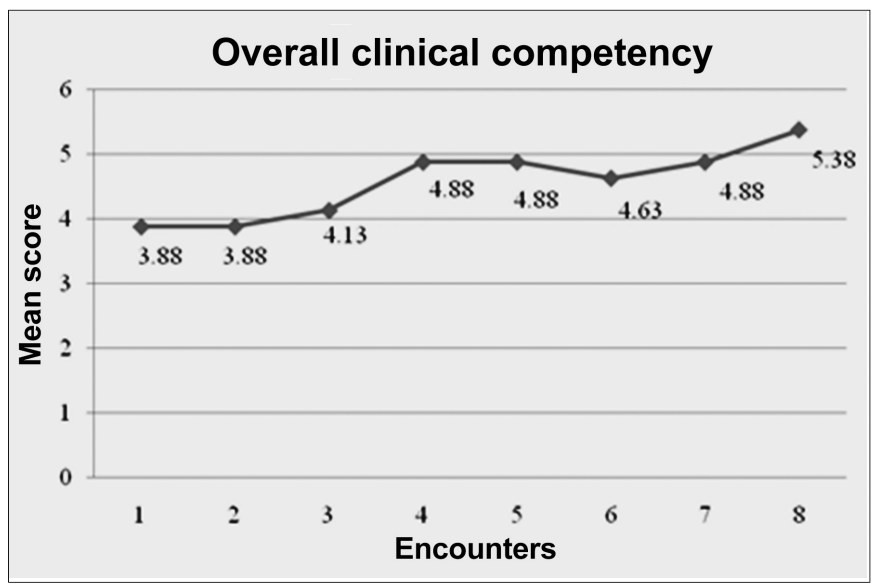

Figure 2: Comparison of overall competency from first to last encounter (p-value 0.000)

cost, the author has studied the educational impact of mini-CEX on residents' learning.

The mini-CEX has been found to be valid and reliable when assessing the core competencies of postgraduate trainees. 8 Out of observation tools used to assess medical trainees' clinical skills with actual patients; the strongest validity evidence has been established for the Mini-Clinical Evaluation Exercise (Mini-CEX). ${ }^{9}$ Its main strength is its in-built ability to provide task related immediate feedback by the learned assessors. 10

The research literature on formative assessment at the workplace and feedback suggests that this is a powerful method for changing the behaviour of trainees. ${ }^{11}$

The high reliability of this tool is attributable to the variety of cases and examiners, and repeated observations. Repeated observations by multiple knowledgeable faculty members on residents' clinical encounter in real workplace followed by instant and focused feedback is essential for performance improvement. Assessment of each resident for eight clinical encounters by multiple faculty members in this study was done to increase reliability and to minimise inter-rater bias.

In this study, significant improvement was observed in all eight domains of assessments. Most profound improvement was seen in organisational efficiency. The most important and effective part of mini-CEX was immediate feedback from the assessor and corrections made therefrom.

Its acceptability by the residents was also found promising. Positive feedback from both, the residents and the assessors, indicates high acceptability of implementation of mini CEX with CEC card system. This high acceptability is similar to some previous studies. ${ }^{12-14}$

Nair et al. reported from their survey on mini-CEX that about $50 \%$ graduates were either satisfied or very satisfied with this assessment strategy for learning. 15 Weller et al. in their study, on the educational impact of mini-CEX in anesthesia residents found that majority of trainees and assessors were satisfied by assessments and the quality of feedback offered. ${ }^{7}$ Khalil et al. have also reported high satisfaction with the mini-CEX tool by both faculty and residents. ${ }^{16}$

In this study, all assessors and residents were satisfied with the conduct of each clinical encounter. The high satisfaction with the mini-CEX by assessors and the residents in this study shows positive progress towards Competency-Based Medical Education (CBME).

All participants, i.e. eight residents and the three assessors $(100 \%)$ were comfortable with CEC system and all $(100 \%)$ agreed on recommending this CEC system to be used in future. Seven out of eight residents $(87.5 \%)$ identified that their PES, oral presentation skills, and history taking/MIS markedly improved through miniCEX. Four residents $(50 \%)$ said that this system helped in building confidence and improve presentation skills in MIS, PES and management. It can help them in preparing for future exams and encourages facing the examiners.

Out of 8 residents, $7(87.5 \%)$ stated that instant feedback helped in the improved learning while one resident opined that instant feedback along with repeated evaluations helped in her improved learning. Two residents $(25 \%)$ suggested that it should evaluate residents of all years.

All residents suggested mini-CEX through CEC should be implemented in training from the beginning of training. 
All three assessors suggested that this system should be part of FCPS training programme as it visibly improved residents' MIS, PES, OE and OCC due to direct observation and immediate and contextual feedback.

Possible limitation of the study might lie in the relatively small sample size. However, statistically significant improvements were observed showing that the power was not compromised. Further larger scale studies are recommended.

The study involved a small group of residents and was conducted in one institution only, thereby limiting the generalisabilty to the residents in other institutions.

However, the assessment of each resident for eight clinical encounters by multiple faculty members has helped us increase reliability and minimize inter-rater bias.

\section{CONCLUSION}

Significant improvement in most of the eight domains observed, assessed and backed up with feedback clearly indicated that there is positive educational impact of mini-CEX implementation on learning of residents in obstetrics and gynecology. Mini-CEX is an acceptable and practical tool for assessment of residents during training. It was found to be feasible within the daily working in OPD and indoor wards. Both faculty and residents have accepted it very well.

Disclosure: The above study has been done as a part of research project for MCPS-HPE after due approval from the HPE faculty of CPSP.

\section{REFERENCES}

1. Singh T, Modi JN. Workplace-based assessment: A step to promote competency based postgraduate training. Indian Pediatrics 2013; 50:553-9.

2. Khanum Z. Effectiveness of reflective exercises for obstetrics and gynaecological residents. J Coll Physicians Surg Pak 2013; 23:468-71.

3. Norcini JJ, Blank LL, Arnold GK, Kimball HR. The mini-CEX (clinical evaluation exercise): a preliminary investigation. Ann Intern Med 1995; 123:795-9.

4. Norcini JJ, Blank LL, Arnold GK, Kimball HR. Examiner differences in the mini-CEX. In: Scherphier AJJA, van der Vlevten CPM, Rethans JJ, van der Skeg AFW (eds). Advances in Medical Education. Springer; 1997. p.170-2.

5. Al-Eraky M, Marei H. A fresh look at Miller's pyramid: Assessment at the 'Is' and 'Do'levels. Med Edduc 2016; 50:1253-7.

6. Williams BW, Byrne PD, Welindt D, Williams MV. Miller's Pyramid and core competency assessment: A study in relationship construct validity. J Contin Educ Health Prof 2016; 36:295-9.

7. Weller J, Jolly B, Misur M, Merry A, Jones A, Crossley JM, et al. Mini-clinical evaluation exercise in anaesthesia training. $\mathrm{Br} J$ Anaesth 2009; 102:633-41.

8. Hatala R, Ainslie M, Kassen BO, Mackie I, Roberts JM. Assessing the mini-clinical evaluation exercise in comparison to a national specialty examination. Med Educ 2006; 40:950-6.

9. Kogan JR, Holmboe ES, Hauer KE. Tools for direct observation and assessment of clinical skills of medical trainees: A systematic review. JAMA 2009; 302:1316-26.

10. Norcini JJ, Blank LL, Duffy FD, Fortna GS. The mini-CEX: a method for assessing clinical skills. Ann Intern Med 2003; 138:476-81.

11. Norcini J, Burch V. Workplace-based assessment as an educational tool: AMEE Guide No. 31. Med Teach 2007; 29:855-71.

12. Singh $T$, Sharma M. Mini-clinical examination (CEX) as a tool for formative assessment. Nat Med J India 2010; 23:100-2.

13. Goel A, Singh T. The usefulness of mini clinical evaluation exercise as a learning tool in different pediatric clinical settings. Int J Appl Basic Med Res 2015; 5(Suppl 1):S32.

14. Chandra M. Initiating formative assessment of postgraduate students in obstetrics \& gynecology. Natl $J$ Integr Res Med 2013; 4:132-7.

15. Nair BR, Alexander HG, McGrath BP, Parvathy MS, Kilsby EC, Wenzel J, et al. The mini clinical evaluation exercise (miniCEX) for assessing clinical performance of international medical graduates. Med J Aust 2008; 189:159-61.

16. Khalil S, Aggarwal A, Mishra D. Implementation of a miniclinical evaluation exercise (Mini-CEX) program to assess the clinical competence of postgraduate trainees in pediatrics. Indian Pediatr 2017; 54:284-7. 